\title{
HET KLEIN-LANDBOUWBEDRIJF EN DE VRUCHTENCULTUUR IN SURINAME
}

\author{
DOOR
}

J. A. LIEMS.

(Landbouwleeraar in Suriname).

In de laatste jaren wordt door Nederland, meer dan vroeger, belangstelling getoond in het lot der Kolonie Suriname. Het steeds grooter wordend jaarlijksch subsidie-cijfer, dat voor 1923 meer dan vier millioen gulden zal bedragen, is voor de Nederlandsche Regeering een prikkel om te trachten de Kolonie uit haar economisch verval op te heffen.

Van de verschillende pogingen door de Regeering aangewend om de Kolonie weer tot welvaart te brengen, is er slechts één die tot werkelijk gunstige resultaten geleid heeft nl. de oprichting van een immigratiefonds. De geregelde aanvoer van arbeiders uit Britsch-Indië en Java, ten behoeve van cultuur-ondernemingen, welke dat fonds mogelijk maakt, heeft tot kolonisatie met deze lieden geleid en op die wijze tot eene aanmerkelijke toeneming der bevolking. Het grootste deel dezer kolonisten toch legt zich - aangemoedigd door de zeer vrijgevige voorwaarden van landuitgifte - op den landbouw toe en vormt met de vroegere negerbevolking der plantages den z.g. klein-landbouwersstand. Dat deze kleinlandbouwersstand thans van groote beteekenis is, blijkt hieruit, dat volgens het Koloniaal Verslag, op 31 Dec. 1920 de door den klein-landbouw bebouwde oppervlakte ruim 22. 500 H.A. bedraagt en 39.000 menschen daarin een bestaan vinden. Deze cijfers bedragen voor den bijna drie eeuwen bestaanden grooten landbouw resp. 12.400 en 13.000 , waarbij in aanmerking moet worden genomen, 
dat bij de eerste meer kinderen en ouden dan bij de laatste voorkomen.

Van de verschillende commissiën en deskundigen, die in de laatste jaren onderzoekingen instelden en daarover rapport uitbrachten, is het alleen de studie-commissie van het Suriname Studie-Syndicaat geweest, die over de beteekenis van den klein-landbouw een oordeel heeft gevormd. Dit onpartijdig en gunstig oordeel van zakenmannen, met veel praktische ervaring, is een gevolg van eigen waarneming en het niet afgaan op mededeelingen van z.g. tot oordeelen bevoegden. Te meer verdient dit oordeel waardeering, omdat het eigenlijke doel van de studiereis niet anders was dan na te gaan of er in Suriname, op zakelijken grondslag, emplooi voor het Nederlandsch kapitaal te vinden zoude zijn.

Verschillende adviseurs hebben verschillende adviezen uitgebracht en plannen ontworpen om deze meest $\mathrm{Ne}$ derlandsche Kolonie uit haar economisch verval op te heffen. De studie-commissie van het S.S.S. b.v. beveelt massalen aanvoer van arbeiders uit Java aan, terwijl de heer Pyttersen (zie zijn rapp. a.d Min. v. Kol.) weer alle heil verwacht van de toepassing van mechanische hulpmiddelen in het landbouwbedrijf.

Beide adviezen hebben groote waarde, elk op zich zelf, en bedoelen voorwaarden te scheppen, waarbij door middel van het Nederlandsche kapitaal de Kolonie in afzienbaren tijd tot bloei kan worden gebracht.

Door de meeste adviseurs is m.i. te weinig aandacht geschonken aan het kapitaal dat in de Kolonie aanwezig is in den vorm van den arbeid door ongeveer 12.000 zelfwerkende gezinnen, die zich met den kleinlandbouw bezig houden.

Dagelijks met deze menschen in aanraking komende, heb ik kunnen ervaren, dat hier een goede kern aanwezig is, waaruit zich een krachtige middenstand kan ontwikkelen als de factoren, welke hier belemmerend werken, worden uit den weg geruimd.

De Studie-commissie van het S.S.S. is blijkbaar dezelfde meening toegedaan. Op blz. 113 van haar rapport zegt zij: 
„De indrukken die wij opdeden van de door het Gouvernement in hoofd„zaak op verlaten plantages gestichte vestigingsplaatsen, bewoond door „Creolen, Br-Indiërs en Javanen, waren boven verwachting. ... . ;

Op blz. 112:

„Van bestuurswege zal al het mogelijke gedaan moeten worden, om de „, bevolking op den komenden economischen strijd voor te bereiden en haar „,sterk te maken. Door het geringe succes, dat tot nu bereikt werd met het „landbouw-onderwijs, de demonstratievelden enz. late men zich niet ont„moedigen; de tijd zal spoedig komen, dat het volk er leering uit zal trek,ken....;

En op blz. 118. :

„Overigens zijn wij van oordeel, dat de middenstands-landbouw door ei„gen kracht moet en zal voortkomen uit den Kleinen-landbouw."

Toen de cacao-cultuur nog behoorlijke winsten opleverde, begon een middenstand zich reeds te ontwikkelen. Vooral in de districten Nickerie, Saramacca en Cottica waren tal van landbouwers, die hunne z.g. grondjes tot kleine plantages van 12 tot $20 \mathrm{H}$.A. wisten uit te breiden en waarop goede woonhuizen voorkwamen. Door het verwoestend optreden der krulloten-ziekte, zijn al deze lieden totaal verarmd. Wel is thans de oorzaak der ziekte bekend en bestrijding mogelijk, maar op de meeste der gronden is de beplanting reeds grootendeels uitgestorven en vrijwel waardeloos geworden.

Tijdens den oorlog is onder den invloed van hooge prijzen der voedingsmiddelen weer eene periode van bloei ingetreden. Vooral de rijstcultuur werd toen sterk uitgebreid en Suriname, dat vóór den oorlog rijst tot een waarde van 1.5 millioen gulden invoerde, kan thans in eigen behoefte voorzien, zelfs uitvoeren.

In een land als Suriname, waarvan iedereen overtuigd is, dat de landbouw de hoofdbron van bestaan voor de groote massa moet uitmaken, is blijvende welvaart alleen te verwachten, wanneer nevens voedingsmiddelen voor het binnenland ook gewassen geteeld worden wier producten, met kans op winst, uitgevoerd kunnen worden, omdat in een zoo schaars bevolkt land de markt voor binnenlandsch gebruik spoedig overvoerd wordt.

Wordt het plan Pyttersen verwezenlijkt en toepassing 
van mechanische hulpmiddelen in den landbouw ook in Suriname mogelijk, dan zal, zooals het S. S. S. opmerkt, in de groote rijstpolders machinale bewerking van den bodem tegen bepaalde prijzen door het Gouvernement, particulieren of in coöperatie kunnen geschieden.

Als staaltje van productiviteit van den bodem vermeldt het S. S. S. de volgende cijfers:

,Van een complex rijstvelden, ter grootte van 367 H.A., in Nickerie, werden in 1918 zonder omwerking van den grond, verkregen 1.084500 K.G. padi = gem. 2955 K.G. per H.A. of \pm 34 pic. per bouw, een mooi gemiddeld voor onbewerkten grond".

Laat mij hieraan toevoegen dat 1918 geen bizonder oogstjaar was en de opbrengst in 1919, dat een zeer goed jaar was, veel hooger is geweest, terwijl op het gebied van selectie nog niets is gedaan.

Aangezien voor de oplossing van het probleem van mechanische bewerking eenige jaren gevorderd wordt, moet worden nagegaan welke producten, waarvan de voortbrenging ook in andere landen alleen door handenarbeid mogelijk is, met kans op winst middelerwijl voor uitvoer in aanmerking komen. Een dergelijk product is de banaan (in Suriname bacove genoemd). Gedurende den zomer van 1921 vonden proefzendingen van Surinaamsche bananen naar Amsterdam plaats. Aangemoedigd door het gunstig on thaal, dat de vruchten op die markt mochten genieten, werden de proeven in den zomer van 1922 herhaald. Hoewel onder de omstandigheden waaronder de vruchten thans vervoerd moeten worden, slechts onvolwassen vruchten verscheept konden worden, staat toch nu reeds vast, dat de Surinaamsche bananen, vooral de Gros-Michel, in kwaliteit uitmunten boven alle tot nu in Nederland aangevoerde soorten. Er worden nu ernstige pogingen in het werk gesteld om bananen uit Suriname, in speciaal daarvoor ingerichte schepen, te vervoeren. Zonder dergelijke schepen is de geregelde aanvoer van volwassen vruchten niet verzekerd. Van de door de Regeering ten deze te verleenen steun, hangt het af of deze pogingen 
tot gunstige resultaten zullen leiden. Bij het verleenen van steun houde de Regeering daarom niet alleen rekening met de belangen van den grooten landbouw, maar ook met die van den klein-landbouw, omdat deze belangen voor de koloniale gemeenschap in geenen deele van minder beteekenis zijn. Terwijl de door den grooten landbouw gemaakte winsten grootendeels - zooals de geschiedenis leert - het land uitvloeien, blijft de winst van den klein-landbouw in de Kolonie, leidt daar tot kapitaalvorming, waaraan voor inheemsch initiatief zoo groote behoefte bestaat.

De heer W. R. Menkman (1) schreef daaromtrent zeer terecht:

„Waren in de dagen toen Suriname nog een „,bloeiende Kolonie” kon hee„ten de Surinaamsche belangen in hoofdzaak plantagebelangen, na 1863 „zijn in Suriname gaandeweg volksbelangen naar voren getreden, welke "geenszins met plantagebelangen mogen worden verward, van hoe groot ge"wicht het ook moet worden geacht dat de groote landbouw door gunstige „,arbeids-toestanden en crediet-voorwaarden gelegenheid hebbe zich staan„de te houden en verder te ontwikkelen. De groote meerderheid der Suri„naamsche inboorlingen heeft bij de plantages rechtstreeks kapitaals„,noch arbeidsbelangen en voor de niet meer onder werkcontract verbonden "Aziatische immigranten geldt hetzelfde; van deze laatste blijtt slechts de min",derheid plantage-arbeid verrichten" $\left.{ }^{2}\right)$.... .

.... „En waar nu in een land als Suriname de landbouw als de hoofd„,bron van bestaan moet worden beschouwd voor de groote massa des volks „treedt vanzelf op den voorgrond het belang van den kleinen-landbouw en "middenstands-landbouw."

Het bevorderen van een herleving van de bacovencultuur in Suriname waarbij de klein-landbouw betrokken wordt, beteekent dus het bevorderen van een groot volksbelang voor de Kolonie, omdat een zeer groot deel van de bij den klein-landbouw in cultuur zijnde gronden voor deze cultuur geschikt en gunstig gelegen is, terwijl de cultuur aan het klein-bedrijf niet vreemd is. Het is aan geen twijfel onderhevig, dat indien de cultuur - zoo als te verwachten is - behoorlijk winstgevend is, deze zich snel zal kunnen uitbreiden en uit den klein-landbouw, evenals vroeger bij de cacao, zich flinke voort-

1) Nederland en West-Indië één, door W. R. Menkman, Amsterdam, Maart 1919.

2) De cursiveering is van mij. 
brengers zullen ontwikkelen, die zich ook op de teelt van andere vruchten als sinaasappelen, ananas en andere voor export in aanmerking komende vruchten zullen kunnen toeleggen.

De heer Pyttersen zegt op blz. 7 van zijn rapport: „De goudwinning, de houtaankap en het balatawinnen verschaffen nog steeds arbeid aan vele Creolen, maar achteruitgang van deze takken van nijverheid valt te constateeren en indien deze zich voortzet, zal althans een deel der bij die nijverheid betrokken arbeiders een bestaan moeten vinden in den landbouw of zullen bepaalde terreinen moeten worden gereserveerd voor het verleenen van vergunningen op kleine schaal aan Creolen om goud te winnen, balata in te zamelen of hout te kappen".

Daar deze laatste bedrijven niet bevorderlijk zijn aan een goed gezinsleven, en ongezond zijn is het van veel belang dat de klein-landbouw in zulke banen geleid wordt, dat zij de vrij komende arbeiders tot zich trekt.

Om aan te toonen dat bij de invoering van de cultuur, waarvan hier sprake is, de klein-landbouw een factor is waarmede degelijk rekening behoort te worden gehouden, diene het volgende:

Aannemende dat voor een driewekelijksche verscheping van 20.000 bossen per keer, eene oppervlakte van 1000 H.A. in cultuur gebracht zal moeten worden, dan zal het groot-bedrijf, dat met aangehuurde arbeiders moet werken, voor den aanleg hiervan 0,5 millioen gulden noodig hebben, terwijl onder de klein-landbouwers, met eenige organisatie, gemakkelijk 2000 perceelhouders, elk voor $0,5 \mathrm{H}$.A. voor het doel gewonnen zullen kunnen worden, die, omdat zij met hunne gezinnen vrijwel allen arbeid zelf verrichten en daardoor goedkoop produceeren, het buitenlandsch kapitaal geheel zullen kunnen ontberen.

Uitbreiding der cultuur, indien noodig, zal snel en gemakkelijk kunnen plaats vinden, zoowel door vergrooting der oppervlakte op de gronden der reeds er bij betrokkenen als door meerdere deelneming.

In het No. van de N.R. Ct van 9 Januari schrijft Dr. 
van Blankenstein: „De bacoven teelt en de vruchtenteelt in het algemeen, bieden vooral den klein-landbouwer een goede gelegenheid tot bijverdienste. Reeds nu kan men in vestigingsplaatsen zelfs langs de wegen rijen van bacovenstoelen zien".

Volgens Dr. van Blankenstein kende men in Suriname de varieteit Gros-Michel in het geheel niet. Dit is niet geheel juist. Zoo als de overzichtschrijver van het Koloniaal Weekblad in het No. van 19 Januari terecht opmerkt, is de Gros-Michel de van ouds bekende bananebacove. Bij den aanleg van de bacoven-cultuur in 1906 is dan ook veel plantmateriaal gebruikt van oude in de kolonie aanwezige stoelen. Een geregelde cultuur van deze variëteit bestond echter niet en ontbrak dus de ervaring omtrent de eischen welke deze stelt. Ik ben het geheel eens met hetgeen verder in het Weekblad staat, vooral, dat men aan geen andere cultuur-methode had moeten denken dan ten aanzien van de in Suriname gekweekte musa-soorten steeds gevolgd werd en zeker niet op eenmaal voor de geheele oppervlakte een nieuwe cultuurwijze moeten voorschrijven, al had men daarmede elders goede resultaten bereikt. De ziekte vernietigde in korten tijd de cultuur over de geheele beplante oppervlakte - met een enkele uitzondering. Die uitzondering en het bij den klein-landbouw in stand geblevene zijn aanwijzingen, dat naar alle waarschijnlijkheid de gevolgde cultuur-methode verkeerd was.

De twee voornaamste voorschriften welke den planters werden opgelegd, waren: intensieve drooglegging - ook in den drogen tijd - van den grond en het omspitten uitteraard ook in den drogen tijd - tot een diepte ongeveer gelijk aan de dikte van de bouwlaag. Bij de oude cultuur-methode werd de bedelving minder diep gemaakt en in den drogen tijd de grond slechts oppervlakkig losgewerkt om de verdamping tegen te gaan. Deze methode voldoet zeker beter aan de behoefte aan water, welke voor de musa-soorten zeer groot is.

Waar de verschijnselen van de Panama-ziekte typische verwelkingsverschijnselen zijn, is het niet onwaarschijn- 
lijk, dat - al moge de intensieve drooglegging van den grond niet de directe oorzaak zijn geweest - de ziekte er toch zeer door werd bevorderd.

Naar aanleiding van de genoemde en andere aanwijzingen, worden thans onder leiding van Prof. Dr. Stahel proeven genomen en is dus de wensch van den schrijver in het Koloniaal Weekblad, dat een proef in het klein met de Gros-Michel, die een buitengewoon mooie vrucht is met vele gewaardeerde eigenschappen, genomen zal worden, reeds vervuld.

Omtrent hetgeen de heer B. J. Kluvers in de W.I. Gids van Januari schrijft, nl. dat de superieure GrosMichel wellicht nog in aanmerking kan komen voor den kleinen landbouw, zij hier aangeteekend, dat volgens door mij uit Suriname ontvangen brieven vele kleine ondernemers bereid zijn de cultuur aanzienlijk uit te breiden, zoodra zij van den afzet verzekerd zijn.

Leiden de pogingen tot vervoer van bananen, met daarvoor ingerichte schepen, tot gunstige resultaten, dan zullen ook proeven genomen kunnen worden met het vervoer van andere vruchten, waarvan ik slechts noem: ananas, manja, en zuurzak. Ook de sinaasappel-export zal dan in afzienbaren tijd sterk kunnen toenemen: le omdat dan gelegenheid zal bestaan de sinaasappel met die schepen onder constante temperatuur te vervoeren, waardoor de overkomst beter verzekerd is; de sinaasappelen rijpen $\mathrm{nl}$. in die maanden, waarin, door natuurlijke oorzaken, de bananen-oogst kleiner wordt; 2e omdat op het ontboscht terrein de winstgevende bananen-cultuur, op zich zelf gedurende enkele jaren gedreven kan worden en daarna de jonge sinaasappel uitgeplant kan worden; bij oordeelkundig uitdunnen der bananen, kan de sinaasappel nog eenigen tijd onbelemmerd groeien, terwijl ook van de bananen nog profijt getrokken wordt; 3 e. wanneer langer aanhouden der bananen, wegens toeneming in omvang der sinaasappelboomen of om andere redenen, niet meer wenschelijk is, de teelt van ananas, waarvan ook goede soorten in Suriname voorkomen, als onderge- 
was mogelijk is en waarvan dan ook het vervoer onder gunstige omstandigheden mogelijk is geworden. Deze bedrijfsvorm is, omdat hij veel zorg en toezicht vereischt, meer voor den middenstander geeigend dan voor het groot-kapitaal.

In 1907 werden voor het eerst proeven genomen met den export van Surinaamsche sinaasappelen naar $\mathrm{Ne}-$ derland. Aangemoedigd door de gunstige resultaten, begonnen enkele landbouw-ondernemingen, voorloopig op bescheiden schaal, zich op de cultuur voor export toe te leggen.Tot dien tijd was er van een cultuur geen sprake. Op de erven van beheerders van cultuurondernemingen en van kleine boeren stonden wel enkele boomen, meestal zaailingen, doch aanplant voor den handel was dit niet. Voor hen, die zich op de cultuur begonnen toe te leggen, was wegens gebrek aan het daarvoor noodige materiaal de mogelijkheid uitgesloten om een aanplant van uitsluitend erkend goede soorten aan te leggen. Die aanplantingen bestaan daarom uit een mengsel van goede en minder goede soorten. De gunstige resultaten, met de eerste zendingen verkregen, werden bij de tot 1911 voortgezette proefnemingen bevestigd en verbeterd. De netto opbrengsten varieerden tusschen 2 en 3 centen per verzonden vrucht. Toen de meer regelmatige aanplantingen tot vruchtdracht kwamen, werd de uitvoer door den oorlogstoestand verhinderd. Eerst in September 1921 kon weer met den export worden aangevangen. Wegens gebrek aan geoefend personeel liet de behandeling en verpakking der vruchten nogal te wenschen over. Toch waren de finantieele resultaten gunstiger dan bij de vroegere proefzendingen. De netto opbrengsten bedroegen 4 tot 7 centen per verzonden vrucht. Door alsnog onbekend gebleven oorzaken, kwamen van den oogst 1922 eenige partijen met ruim $25 \%$ bederf te Amsterdam aan. Toch was de netto opbrengst nimmer beneden 2.5 cent per verzonden vrucht. De op 7 November j.l. te Amsterdam geveilde vruchten, welke in goeden staat aankwamen, brachten bruto 7 cents per vrucht voor de middelsoort en 16 cents voor de zeer groote soorten op. 
Op de Jaarbeurs te Utrecht van 4-9 September j.l. zijn de Surinaamsche sinaasappelen uitgestald geweest, terwijl het publiek in de gelegenheid werd gesteld om over den smaak te oordeelen. Dit oordeel was over het algemeen zeer gunstig.

De cultuur in Suriname is - als reeds gezegd - nog jong en hierdoor konden nog niet, als in andere sinaasappelen-produceerende landen, speciale soorten met erkend goede eigenschappen voor bepaalde markten gekweekt worden. Toch beschikken wij er over enkele soorten, die zoowel in Europa (Nederland, Stockholm en Kopenhagen) als in Noord-Amerika zeer gunstig beoordeeld zijn. Het Departement van den Landbouw in Suriname heeft thans eenige tienduizende onderstammen in den grond, waarop in het a. s. seizoen deze goede soorten geënt zullen worden ten behoeve van hen, die zich op deze cultuur wenschen toe te leggen. De jonge aanplant laat de cultuur van tusschengewassen toe en dit maakt met de zorgvuldige behandeling, welke de vruchten vereischen, van het plukken af tot de verpakking toe, de cultuur bij uitstek voor den middenstander geschikt. Het sorteeren en verpakken verschaft aan het gezin gelegenheid tot nuttigen arbeid binnenshuis.

Volgens een door het Departement van den Landbouw in Suriname, voor een groot bedrijf, gemaakte kostenraming voor aanleg en onderhoud tot het rendabel worden der onderneming, is ongeveer $f 2000$. per H.A. benoodigd. Daarbij is zeer weinig rekening gehouden met tusschen-cultures.

Voor den middenstander, die scherper toezicht op de uitgaven heeft en beter in de gelegenheid is om van tusschen-cultures voordeel te trekken, zullen de kosten tot $f 1200$, en minder, per H.A. zijn terug te brengen.

In ,the Rural Science Series; Editor L. H. Bailey is in 1920 verschenen: het werk "Citrus Fruits" van J. Eliot Coit. M. S. A., Ph. D. (Prof. of Citri-culture in the University of California enz.) waarin de kosten van een 10 Acre groote boomgaard van sinaasappelen op 6250 
dollars gesteld worden. (1 acre bedraagt slechts weinig meer dan 0,4 H.A.)

Voor kleine bedrijven is land op zeer gunstige voorwaarden te bekomen op z.g. centrale vestigingsplaatsen, d. $z$. ingepolderde landerijen, waar de kosten voor onderhoud der afwateringswerken door het Gouvernement worden gedragen.

Behalve de gunstige voorwaarden tot verkrijgen van land, biedt Suriname nog het voordeel van het gemakkelijk en goedkoop watertransport aan. Dure irrigatie als in Californie of kunstmatige bescherming tegen vorst als in Florida zijn er niet noodig. De loonen zijn in Suriname veel lager dan in deze beide staten en zeker niet hooger dan in Spanje. Voor een klein bedrijf is het, met den noodigen tact om met arbeiders om te gaan, mogelijk een klein aantal losse arbeiders in dienst te nemen tegen loon varieerend tusschen $f 1$. en $f 2$ per dag, terwijl voor stukwerk in overeenstemming hiermede het loon geregeld wordt. Aan kleine ontginners kunnen ook gecontracteerde Javaansche arbeiders worden toegewezen, welke door tusschenkomst van het Koloniaal gouvernement worden aangevoerd. Aan het Immigratie-fonds is de planter voor dergelijke arbeiders verschuldigd 15 cents per dag waarop gewerkt is en een loon dat varieert van $f 0.80$ tot $f 1$. per dag. Men kan rekenen, dat dergelijke arbeiders te staan komen op $f 1.25$ per verrichte dagtaak.

Volgens de hooger genoemde raming van het Departement van den landbouw, is de opbrengst gesteld op 1.5 cents per vrucht netto te Amsterdam. Met de thans opgedane ervaring, mag deze hooger en wel op minstens 2 cents gerekend worden, en zal bedragen:

$$
\begin{aligned}
& \text { in het } 5 \text { e jaar } f \text { 112.- per H.A. } \\
& \text { ", 6e , , 224.— , , } \\
& \text {, " 7e , , 448.- , , } \\
& \text {, " 8e , , 672.- , , } \\
& \text { " " } 9 \text { e , ,1120.- " , } \\
& \text { ", 10e , , 1568.- , , }
\end{aligned}
$$

Hierbij is niet in rekening gebracht de hoogere op- 
brengst welke het gevolg moet zijn van het aanbieden van vruchten van betere kwaliteit, dan nu mogelijk was.

De onderhoudskosten zijn, voor den middenstander, te stellen op $f$ 150. per jaar, per H.A. voor volwassen boomen.

Het verrichten van zwaren veldarbeid in een klimaat als dat van Suriname, is voor den Europeaan, op den duur onmogelijk. Voor landverhuizers zonder middelen, die zich door handen-arbeid moeten opwerken, biedt dit land geen toekomst. Maar voor boerenzoons, die gewoon zijn de handen uit de mouw te steken en in het bezit van eenige duizende guldens, zooals er b.v. naar Zuid-Afrika emigreeren en die dus de noodige hulpkrachten voor het zwaarste werk kunnen aanhuren, bestaat.er thans $\mathrm{m}$. i. alle reden om eene vestiging als fruittelers in Suriname in overweging te nemen.

Van de verschillende rassen die in Suriname den landbouw uitoefenen, zijn de Creolen, de Britsch-Indiërs en Javanen de voornaamste.

Over de Creolen is de meening van de meeste schrijvers niet gunstig. Vooral wordt hun afkeer van den plantagearbeid verweten. We zien echter, dat de Aziatische immigranten na afloop der werkverbintenis de plantages eveneens verlaten. Een meer gegrond verwijt is, dat de door de vrijgekomen slaven aangelegde grondjes door hunne nakomelingen meerendeels verlaten zijn of aan Br.-Indiërs overgedragen, om zich in of nabij de stad te vestigen. Gelukkig is hierin een kentering gekomen en is in de laatste jaren zelfs een trek in omgekeerde richting waar te nemen. Inzonderheid door de verbetering van het onderwijs in de districten, blijven de kinderen, meer dan vroeger, op de grondjes bij de ouders en groeit er een geslacht op, dat niet geheel van het bedrijf der ouders vervreemdt. Daarom wordt hier met nadruk herhaald wat door den heer Menkman in b. a. brochure is gezegd, nl.:

„De Surinaamsche bevolking tot meerderen voorspoed te brengen door ,aanmoediging van kleinen en middenstandslandbouw mag een Suri„,naamsch volksbelang worden genoemd bij uitnemendheid." 
„De onderwijs-politiek, de grond-, de belasting-, de crediet-, de wegen„politiek zullen hoe langer hoe meer op dit belang gericht moeten wor„den".

Zelfs de heer Pyttersen, die over den Creool als landbouwer ongunstig oordeelt, zegt:

„Zij die van nabij de Creolen in de bosschen hebben zien werken, zullen „moeten erkennen, dat dezen voor de aldaar te verrichten werkzaamheden "goede eigenschappen bezitten."

Er is m.i. geen enkele reden om aan te nemen, dat de Creool voor den niet minder inspanning vereischenden arbeid in de bosschen goede eigenschappen zoude bezitten en voor den landbouw niet, indien hij in dit bedrijf hetzelfde loon kan verdienen.

Veel juister is het oordeel van hetS.S.S.,datals volgtluidt :

„Aangelokt door de hooge prijzen is er tijdens den oorlog meer liefhebbe„rij bij de Creolen voor den landbouw gekomen. Uit de hoofdplaatsen zijn ,velen naar het land getrokken. Een groot deel faalde - de Creool is geen "landbouwer in zijn hart - maar met aanmoediging door het bestuur en "voorlichting van de landbouwleeraars wordt de tegenzin misschien ge,leidelijk overwonnen en zal ook de Creolenbevolking zich langzaam aan "meer op den landbouw gaan toeleggen. Voor dit in andere bedrijven zoo ",bruikbare volk is zulks zeer te hopen."

De tegenzin is niet zeer groot en wordt hoofdzakelijk gevoed doordat de Creool onder de tegenwoordige omstandigheden, d. w. z. zonder voldoende bedrijfszekerheid, geen kans ziet om in den landbouw een behoorlijk bestaan te vinden. Een groot deel van hen die naar het land trekken, falen wegens gebrek aan vakkennis en ongeoefendheid. Bestaat er een middenstand waar zij, die naar het land trekken, tegen behoorlijk loon emplooi en een goed voorbeeld vinden, de meesten zullen dan voor den landbouw gewonnen worden.

De grondpolitiek in Suriname is voor de ontwikkeling van een middenstand niet gunstig. Doch dit onderwerp, is er een waarop de Staats-Commissie van 1911 in haar rapport van September van dat jaar reeds zoo uitvoerig en zakelijk gewezen heeft, dat ik kan volstaan met daarnaar te verwijzen.

Intusschen blijkt hieruit alweer, dat zelfs algemeen noodig geachte verbeteringen op zich laten wachten, ook al komen de voorstellen daartoe van hoogst bevoegde zijde 
en al zou de invoering daarvan geen noemenswaardige uitgave, ja, zelfs, als in dit geval, tot aanzienlijke voordeelen: de opheffing van de kern der bevolking, leiden.

Het vorenstaande samenvattend, komen wij, met betrekking tot Suriname's economischen opbouw, tot het volgend resultaat:

le. naast de eeuwenoude cacao-, koffie- en suikercultuur, die, zooals het verleden aantoont, bij voortduring aan ups, doch nog meer aan downs onderhevig is, andere cultures invoeren, die, omdat zij als het ware de specialiteit van het land vormen, een ruim afzetgebied, een zekerder markt zullen vinden en daaronder op de allereerste plaats te beproeven: cultures voor den uitvoer van bananen, sinaasappelen, ananassen en andere vruchten;

2e. dat bij het invoeren dier cultures niet meer uitsluitend noodig zijn buitenlandsch kapitaal en uit Azië aangevoerde arbeidskrachten, doch ook gerekend mag worden op de in de Kolonie aanwezige ruim 12.000 eigenaren, huurders en gebruikers van perceelen land, groot 1.5 tot 25 H.A., die slechts op de juiste economische mobilisatie wachten om krachtig deel te nemen aan den economischen, maatschappelijken en politieken opbouw der Kolonie;

3e. dat ten opzichte van den landbouw, Suriname op een keerpunt is gekomen en dat bij het beramen van middelen om de Kolonie uit haar verval op te heffen, nevens de plantagebelangen, meer dan tot dusver, ook de volksbelangen, waaronder inzonderheid moeten worden verstaan de belangen van den klein-landbouw, aandacht verdienen;

4e. dat het geld thans door Nederland besteed aan bananen enz. uit vreemde landen, naar eigen kolonie geleid zoude kunnen worden en tot meerdere welvaart van eigen onderdanen bijdragen.

5e. dat, indien er gelegenheid bestaat voor vervoer van vruchten in schepen met koelruimen, ook Nederlanders zich, als fruittelers, in Suriname zullen kunnen vestigen.

Den Haag, Januari 1923. 